\title{
Benign Phyllodes Tumor With Cystic Squamous Metaplasia: A Cytohistological Correlation of a Rare Case
}

\author{
Indranil Chakrabarti ${ }^{1 *}$, Priyanka Agarwala ${ }^{1}$, Pranati Bera ${ }^{1}$, Sankarsan Bhaduri ${ }^{2}$ \\ 1. Dept. of Pathology, North Bengal Medical College, The West Bengal University of Health Sciences, Siliguri, \\ Darjeeling, West Bengal, India \\ 2. Anadaloke Sonoscan Centre, Siliguri, Darjeeling, West Bengal, India
}

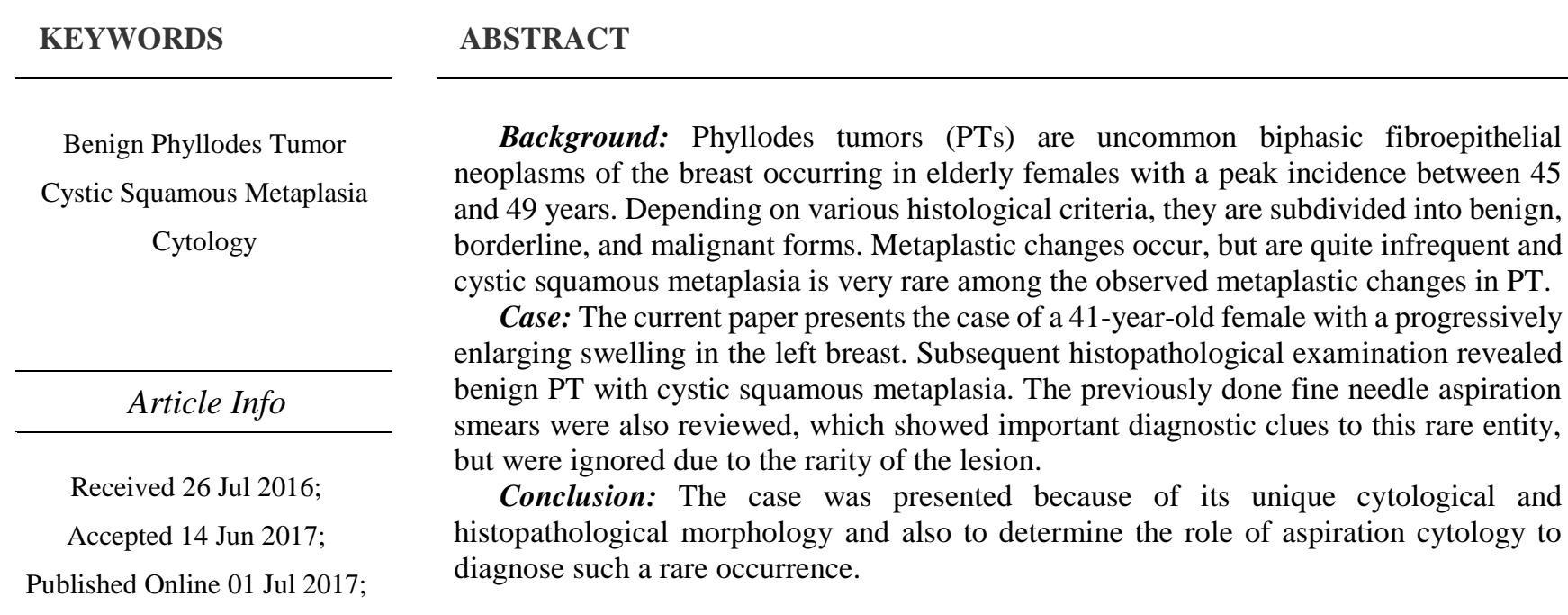

Corresponding Information: Dr. Indranil Chakrabarti, 1.Dept. of Pathology, North Bengal Medical College, The West Bengal University of Health Sciences, Siliguri, Darjeeling, West Bengal, India. Email: drinch@ rediffmail.com Tel/fax: +919433187448.

Copyright ( 2017 , IRANIAN JOURNAL OF PATHOLOGY. This is an open-access article distributed under the terms of the Creative Commons Attribution-noncommercial 4.0 International License which permits copy and redistribute the material just in noncommercial usages, provided the original work is properly cited.

\section{Introduction}

Phyllodes tumors (PTs) are a group of circumscribed biphasic fibroepithelial tumors characterized by a double layered epithelial component surrounded by an overgrowing hypercellular mesenchymal component organized in leaf-like structure. ${ }^{[1]}$ These are uncommon tumors accounting $0.3 \%$ to $1 \%$ of all primary breast tumors (1), with the overall incidence of $2.1 /$ million (2). The peak age of incidence is 40 to 50 years overall (1), whereas in Asian countries it occurs in younger ages (average 25 to 30 years) (3). PT can be subclassified histologically as benign, borderline, and malignant according to features such as tumor margins, stromal overgrowth, necrosis, cellular atypia, and the number of mitoses per high-power field (4). Metaplastic changes can be observed in PT in epithelial or stromal components. The stroma may show cartilaginous, osteoid, or lipomatous metaplasia, while epithelium may occasionally show apocrine or squamous metaplasia (5), of which cystic squamous metaplasia is very rare, accounting only $10 \%$ of PT, making PT with cystic squamous metaplasia an extremely rare primary breast tumor $(6,7)$.

\section{Case report}

A 41-year-old female referred to the surgical outpatient department with chief complaints of swelling in the left breast of five years' duration, which rapidly increasing in size for the last four months with no history of trauma or any constitutional symptoms.

Her general and systemic examination was within normal limit. Local examination showed a welldefined irregular mass of $9 \mathrm{~cm}$ in diameter approximately, not fixed to the skin or chest wall, firm in consistency, but soft at places and tender on palpation. Ultrasonograhic evaluation revealed an 8.9 x 6.6 x $3.9 \mathrm{~cm}$ heterogeneous soft tissue mass in retroareolar and periareolar regions of the left breast. 
The mass was excised and sent to the Department of Pathology, North Bengal Medical College, The West Bengal University of Health sciences, India for histopathological examination.

\section{Gross examination}

Gross examination showed a mass with attached overlying skin measuring $10 \times 7 \times 6 \mathrm{~cm}$. Serial cut sections revealed multiple cystic spaces with mucoid material and few cysts containing whitish material and well defined whitish homogenous areas with one area showing leaf-like mass projecting inside a cystic cavity (Figure 1).

\section{Microscopic examination}

Multiple sections were taken from representative areas, processed, and examined. The periphery of the tumor was well-circumscribed. The sections showed features of benign PT characterized by stromal hypercellularity and stromal overgrowth. There was no cellular atypia and mitotic activity was low. The sections also revealed multiple cystic and glandular spaces enclosed within cellular stroma. The spaces were lined by multilayered benign squamous cells and the cystic spaces were filled with keratin material (figures 2 and 3). Preoperative fine-needle aspiration cytology (FNAC) was performed in a private diagnostic centre. The slides were reviewed and they showed features suggestive of benign phyllodes tumor with cystic squamous metaplasia, which was consistent with the histopathological findings (Figure 4).

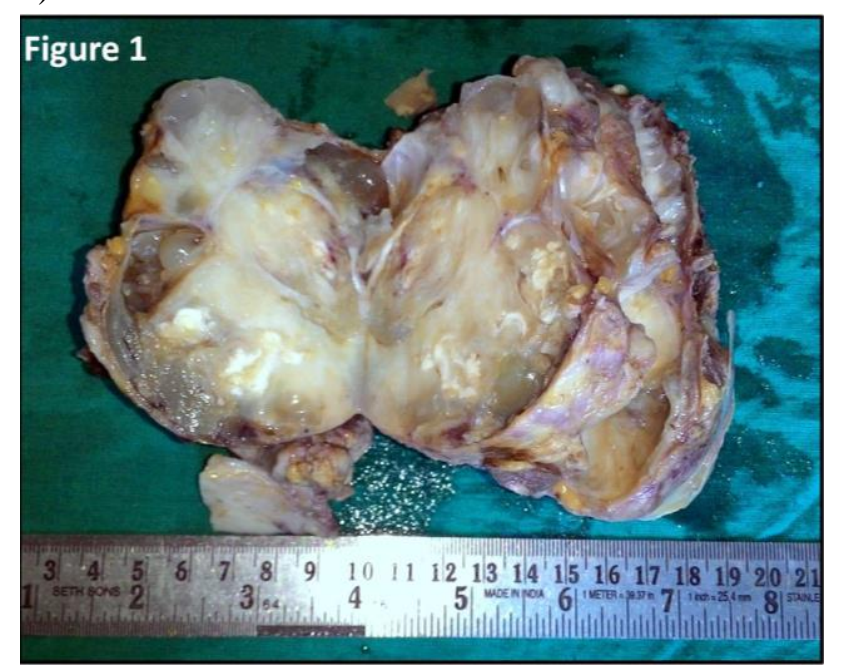

Figure 1. Gross examination of cut section showing mucoid areas and cystic spaces with whitish material within the solid tumor mass

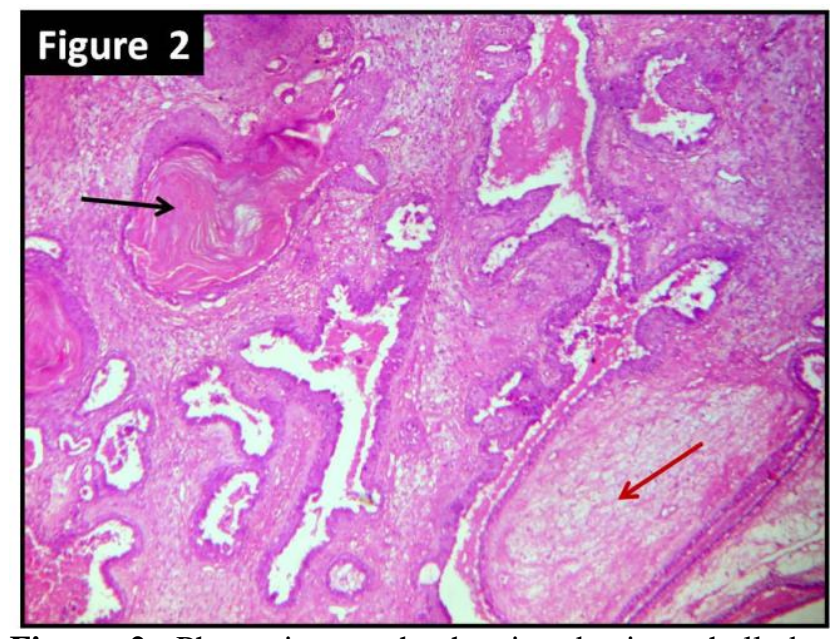

Figure 2. Photomicrograph showing benign phyllodes tumor (red arrow) with squamous epithelium lined cystic spaces with lamellated keratin (black arrow)

(hematoxylin and eosin stain; X100 magnification)

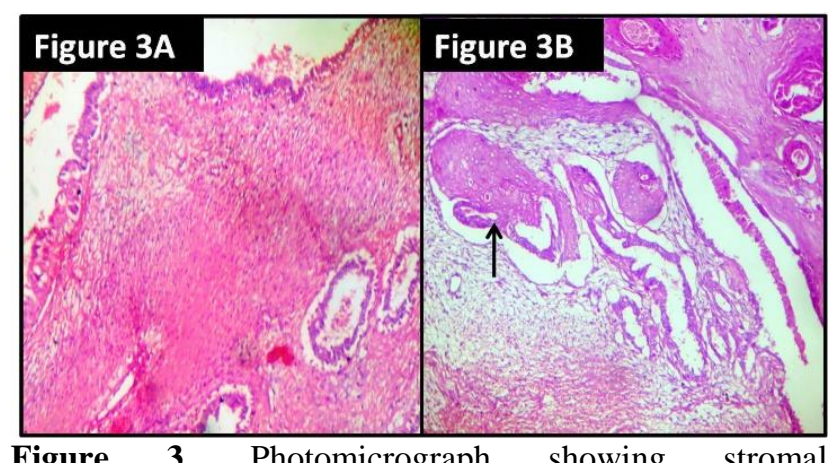
hypercellularity (Figure 3A) and ductal epithelium showing squamous metaplasia (Figure 3B) (hematoxylin and eosin stain; X100 magnification)

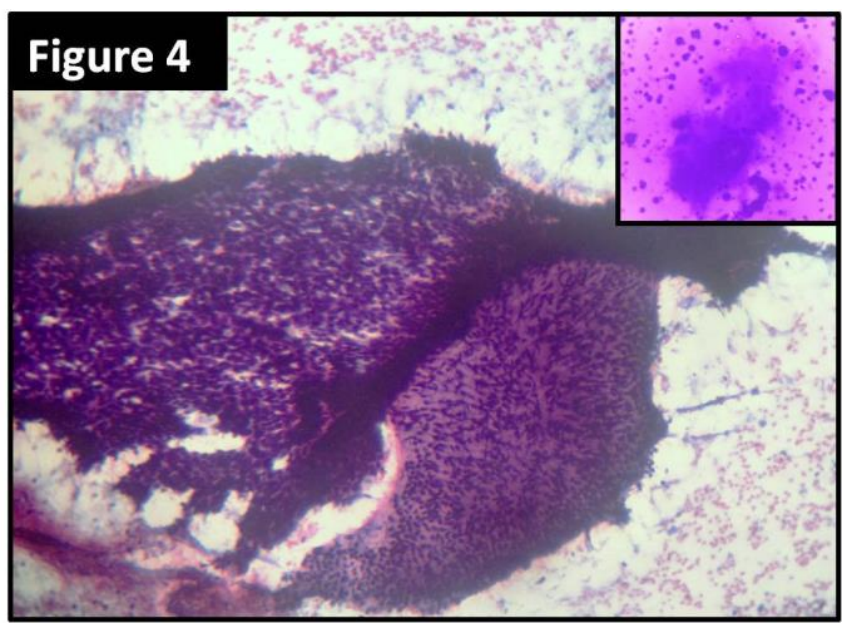

Figure 4. Photomicrograph from cytological smears show hypercellular fragments of benign phyllodes tumor (hematoxylin and eosin stain; X100 magnification) Inset shows keratinous material (Leishman stain) 


\section{Discussion}

PTs, uncommon biphasic fibroepithelial neoplasms (8), usually occur in females aged 45 to 49 years $(9,10)$, but can also occur in younger adults and adolescents (11). World Health Organization (WHO) classified PT into benign, borderline, and malignant, based on histological characteristics that include degree of stromal cellular atypia, degree of stromal overgrowth, mitotic activity per 10 high power fields, tumor necrosis, and margin appearance (the first 3 being the main parameters) (12). Metaplastic changes are infrequent in the stromal and epithelial components of PT (13). In one of the reported PT series, 11 out of 335 cases (3.3\%) showed malignant heterologous components such as osteosarcoma, liposarcoma, and rhabdomyosarcoma. The epithelial component infrequently showed usual-type epithelial hyperplasia, epithelial squamous metaplasia observed in 12 cases (3.6\%), and apocrine metaplasia. Five out of 12 cases with squamous metaplasia revealed squamous cysts. FNAC from cystic areas of tumor may lead to a mistaken diagnosis of squamous cyst (13). Other than PTs, cases of extensive squamous metaplasia in the epithelium of gynecomastia and benign breast papillomatosis were reported $(14,15)$. Differential diagnosis of PT includes fibroadenoma with cellular stroma, adenoma, hamartoma, lipoma, juvenile papillomatosis, carcinoma, sarcomas, and metastasis (12). Histologically, fibroadenomatous stroma is usually homogenous, and it is important to distinguish it from PTs, which can exhibit considerable stromal heterogeneity (16). It is suggested that the development of squamous metaplasia in the breast begins within the myoepithelial cell layer, as supported by immunohistochemical studies (by expression of actin, vimentin, and S-100 protein in the metaplastic squamous cells) (13).

\section{Conclusion}

Hence, the current case was presented due to its unique cytological and histopathological morphology and also to determine the role of aspiration cytology to diagnose such a rare occurrence.

\section{Conflicts of Interest}

The authors declare no Conflict of Interests.

\section{References}

1. Bellocq JP, Magro G. Fibroepithelial tumours. In: Tavassoli FA, Devilee P, editors. World Health Organization Classification of Tumours. Pathology and Genetics of Tumours of the Breast and Female Genital Tract. Lyon: IARC Press; 2003. pp. 99-103.

2. Bernstein L, Deapen D, Ross RK. The descriptive epidemiology of malignant cystosarcoma phyllodes tumors of the breast. Cancer 1993 May;71(10):3020-4.

3. Chua CL, Thomas A, Ng BK. Cystosarcoma phyllodes-Asian variations. Aust N Z J Surg 1988 Apr;58(4):301-5.

4. Rosen PP. Rosen's Breast Pathology. 2nd ed. Philadelphia: Lippincott Williams \& Wilkins; 2001.

5. Sugie T, Takeuchi E, Kunishima F, Yotsumoto F, Kono Y. A case of ductal carcinoma with squamous differentiation in malignant phyllodes tumor. Breast Cancer 2007;14(3):32732.

6. Grimes MM. Cystosarcoma phyllodes of the breast: histologic features, flow cytometric analysis, and clinical correlations. Mod Pathol 1992 May;5(3):232-9.

7. Norris HJ, Taylor HB. Relationship of histologic features to behavior of cystosarcoma phyllodes. Analysis of ninety-four cases. Cancer 1967 Dec;20(12):2090-9.

8. Quinlan-Davidson S, Hodgson N, Elavathil L, Shangguo T. Borderline phyllodes tumor with an incidental invasive tubular carcinoma and lobular carcinoma in situ component: a case report. J Breast Cancer 2011 Sep;14(3):237-40.

9. Salvadori B, Cusumano F, Del Bo R, Delledonne V, Grassi M, Rovini D et al. Surgical treatment of phyllodes tumors of the breast. Cancer 1989 Jun;63(12):2532-6.

10. Bernstein L, Deapen D, Ross RK. The descriptive epidemiology of malignant cystosarcoma phyllodes tumors of the breast. Cancer 1993 May;71(10):3020-4.

11. Rajan PB, Cranor ML, Rosen PP. Cystosarcoma phyllodes in adolescent girls and 
young women: a study of 45 patients. Am J Surg Pathol 1998 Jan;22(1):64-9.

12. Mishra SP, Tiwary SK, Mishra M, Khanna AK. Phyllodes Tumor of Breast: A Review Article. ISRN Surgery 2013;2013:18. https://doi.org/10.1155/2013/361469.

13. Kumar H, Iqbal MB, Buch A, Panicker N. Extensive squamous metaplasia in a benign phyllodes tumor: A rare case report. Med J DY Patil Univ 2015;8(3):404-6.
14. Gottfried MR. Extensive squamous metaplasia in gynecomastia. Arch Pathol Lab Med 1986 Oct;110(10):971-3.

15. Söderstrom KO, Toikkanen S. Extensive squamous metaplasia simulating squamous cell carcinoma in benign breast papillomatosis. Hum Pathol 1983 Dec;14(12):1081-2.

16. Rosen PP. Fibroepithelial Neoplasms. In: Pine JW, editor. Rosen's Breast Pathology, $3^{\text {rd }}$.

17. Philadelphia. Lippincott Williams \& Wilkins; 2009. pp. 202-26.

\section{How to Cite This Article:}

Chakrabarti I, Agarwala P, Bera P, Bhaduri S. Benign Phyllodes Tumor With Cystic Squamous Metaplasia: A Cytohistological Correlation of a Rare Case. Iran J Pathol. 2017;12(3):291-294. 